\title{
Macro-Micro Mechanical Behavior of a Highly-Particle-Filled Composite Using Digital Image Correlation Method
}

\author{
Pengwan Chen, Zhongbin Zhou and Fenglei Huang \\ State Key Laboratory of Explosion Science and Technology, \\ Beijing Institute of Technology, Beijing 100081,
}

China

\section{Introduction}

Particle reinforced composites represent a large group of materials used in a variety of applications, such as concretes and solid rocket propellant. The mechanical behavior of these materials depends on properties of constitutes and any microstructural changes that may occur in the body under loading. Generally, particles are applied to high stress in these composites. Heterogeneity plays an important role in composite fracture. Because the mechanical properties of dispersed phase and matrix differ from each other, any one of the following micro-damage nucleation mechanisms has been observed during the deformation process, including cracking of particles, debonding at the particle-matrix interface and fracture of the matrix. In addition, failure also depends on the volume ratio of particles to matrix.

The polymer bonded explosive (PBX) is a highly filled composite material of crystalline high explosives (90\%-95\% by weight) in polymer binder. This matter is a kind of functionally energetic materials being used increasingly as energetic fillings in both civil and military applications when a very high performance is required. The mechanical properties of PBX subjected to a range of conditions are important criteria to determine a safe working life. The study on the mechanical properties and the failure mechanisms of PBX has drawn much attention in recent years [1-9]. Low strengths and safety concerns bring additional difficulties in preparing samples and conducting mechanical tests of PBX. Therefore, the fracture behavior and the failure mechanisms of PBX are not full understood, some beneficial works are still need to be done to bring some further insights into this issue.

There are many techniques to measure the deformation in experimental test. Strain gauge and extensometer are widely used, while the microstructure deformation can not be provided by these techniques. Significantly, the strain gauge measures the deformation at a single point, which only gives information at one point, and the gauge may provide local reinforcement causing error in the displacement measure. Several high resolution and noncontact optical techniques do have the advantages that they can measure the whole displacement and strain field providing deformation information, and it is enough to follow strains until failure. In recent years, many beneficial works have been reported from Cavendish Lab. The quasi-static deformation fields were measured by this technique. The influence of particles microstructure was found to be significant for its fracture behavior 
[6-7, 10-12]. Rae et al. [13] used DIC to investigate the effect of thermal aging on a UK PBX containing nitrocellulose. And in Rae et al. [5], the method is described in detail including an extended discussion on error analysis. Specially, the deformation and fracture behavior of PBX was studied using the DIC technique at the micro-scale combined with an optical microscope or an SEM imaging system [8-9, 14]. Moreover, the DIC method was used to study the dynamic fracture behavior and mechanical properties of PBX at high-strain rate [15-17].

In this work, a series of quasi-static tests, including Brazilian test, semi-circular bending test, uniaxial compression and punch loading tests, were carried out to study the deformation and fracture behavior of a PBX simulation material, which is a highly-particle-filled composite in which the explosive particles are replaced by simulant particles at $90 \%-95 \%$ weight, with a few percent binder of fluorine rubber. The PBX simulant powder was hot pressed in a steel mold, and then a short, cylinder-shaped specimen can be obtained with 20 $\mathrm{mm}$ diameter. The test specimens were machined from the original cylindrical specimens. The DIC technique was used to digitally process the speckle's movement to determine the full displacement and strain fields. The vector field of displacement can be used to display the failure mechanisms of specimens, and the strains distribution can be used to predict the initiation and propagation of cracks. In addition, an SEM imaging system was used to in situ examine the microstructure of PBX simulant. The microscopic damages, such as debonding, particle's fracture, were observed. The method combing SEM imaging system with DIC technique was used to determine the strain fields of specimens at micro-scale, with the aim at predicting the propagation of cracks with possible developing paths in a splitting fracture of brittle failure.

\section{Principle of digital image correlation}

Digital image correlation (DIC) method is a rapidly developing technique of optical mechanics. It is worth noting that in recent years, it has been widely used to measure the surface deformation field in experimental mechanics for its advantages of no contacting, high accuracy, real time and full deformation field measurement. In the system, a random speckle pattern must need for DIC technique to calculate the deformation field. A CCD camera and a personal computer were used to capture the movement of speckles in situ before and after a deformation. By comparing the speckle pattern in the objective configuration with the speckle pattern in the initial configuration, the displacement and strain full-field can be determined. The algorithm of DIC technique has been developed by many authors [18-20]. The matching theory of this method is given in Fig. 1.

Quadrangle $S$ (solid line) is a reference (or undeformed) sub image and quadrangle $S_{1}$ (dash line) is the corresponding deformed sub image. In order to obtain the displacement $u_{m}$ and $\mathrm{v}_{\mathrm{m}}$ of point $\mathrm{M}$, sub image $S_{1}$ is matched with sub image $S$ using a correlation operation. If subset $\mathrm{S}$ is sufficiently small, the coordinates of points in $S_{1}$ can be approximated by firstorder Taylor expansion as fellows [21]

$$
\begin{aligned}
& x_{n 1}=x_{m}+u_{m}+\left(1+\left.\frac{\partial u}{\partial x}\right|_{M}\right) \cdot \Delta x+\left.\frac{\partial u}{\partial y}\right|_{M} \cdot \Delta y \\
& y_{n 1}=y_{m}+v_{m}+\left(1+\left.\frac{\partial v}{\partial x}\right|_{M}\right) \cdot \Delta x+\left.\frac{\partial v}{\partial y}\right|_{M} \cdot \Delta y
\end{aligned}
$$




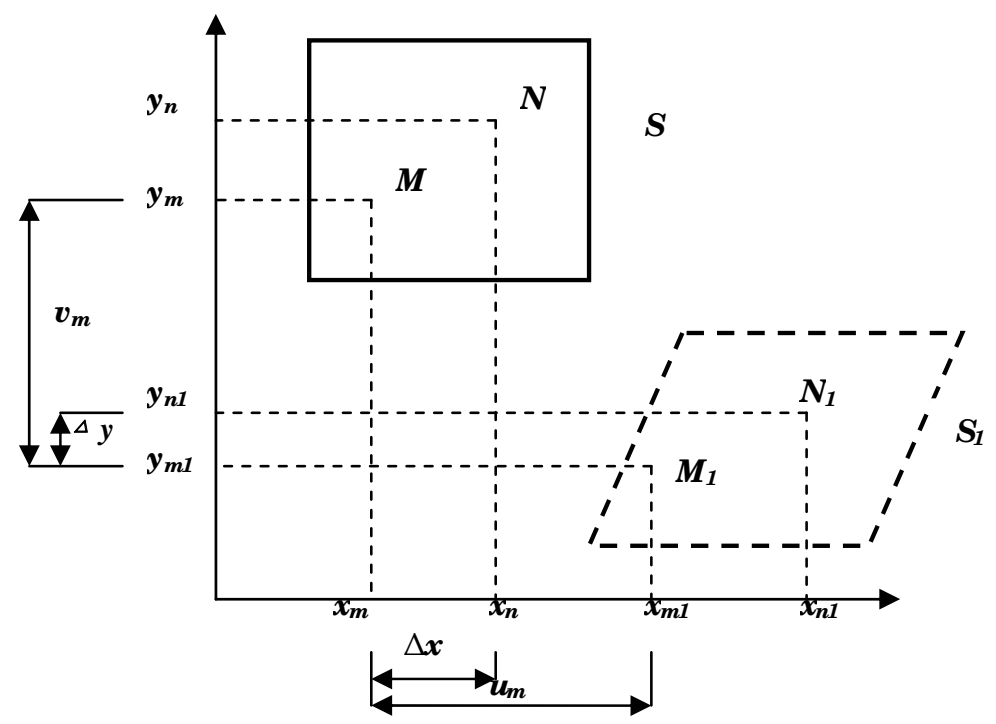

Fig. 1. Schematic diagram of deformed process for planar object

The criterion for comparing two images is commonly given by using the cross-correlation coefficient, which can be written in form as [22]

$$
C=1-\frac{\sum f(x, y) \cdot \sum g\left(x^{*}, y^{*}\right)}{\sqrt{\sum f^{2}(x, y) \cdot \sum g^{2}\left(x^{*}, y^{*}\right)}}
$$

where $(x, y)$ and $\left(x^{*}, y^{*}\right)$ are Cartesian Coordinates of a material point in the image of the undeformed and deformed patterns, respectively. $F(x, y)$ and $g\left(x^{*}, y^{*}\right)$ are light intensities at that point in the corresponding images. The correlation value $C$ varies from 0 to 1 , with 0 signifying a perfect match between the two images.

\section{Experiments}

\subsection{Brazilian test}

The Brazilian test is used for making the testing of uniaxial dumbbell specimens impractical. It is a biaxial method for estimating the tensile failure stress of a material by applying a pair of compressive loads $P$ diametrically to a disc-shaped specimen. A vertical tensile failure is generated in the center region of the specimen along the loading axis, as shown in Fig. 2. According to simple elasticity theory, the tensile stress at the center of the disc is given by

$$
\sigma_{t}=\frac{2 P_{m}}{\pi D \delta}
$$

where $P_{m}$ is the maximum applied force. $D$ is the diameter of the disc specimen and $\delta$ is the thickness. 


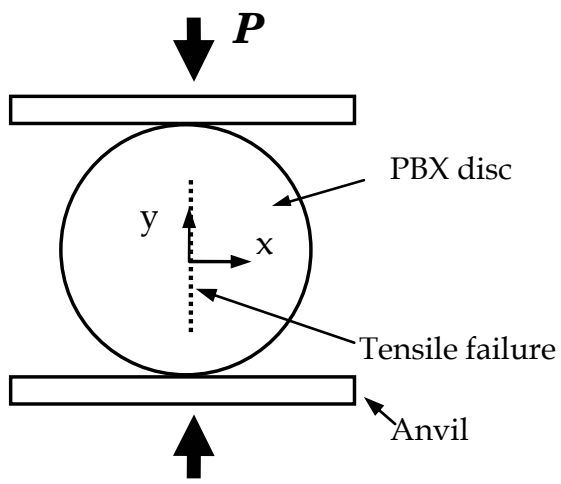

Fig. 2. Brazilian test geometry

\subsection{Uniaxial compression}

Quasi-static uniaxial compression tests were conducted on PBX simulants with the aim at understanding the different failure mechanisms and characterizing the material to allow a valid fracture computational model design. In compression, the cylindrical specimens with $20 \mathrm{~mm}$ diameter and $30 \mathrm{~mm}$ height were machined into block specimens with different aspect ratios. In this work, we focus on the study of the deformation and fracture behavior of block specimens under uniaxial compression action. Combining with the DIC technique, the full displacement and strain fields are to be obtained with significant interests to reveal the strain component distribution, which can be used to predict the propagation of the induced crack with possible failure path.

\subsection{Semi-circular bending (SCB) test}

Standard methods are available for determining the plane strain fracture toughness of metallic materials. The direct application of such standard methods to brittle materials, e.g. rocks and concretes, is also acceptable. However, it is difficult to machine the specimen because the brittle materials are low strength and low mechanical impendence. In order to determine the brittle material's behavior, a typical geometry of the specimen should be utilized for the testing. Since the material is weak in tension, tests should preferably be done with compressive loading where tensile fracture is induced. To satisfy this requirement, Chong and Kuruppu [23] proposed a bending test by using a semi-circular specimen with a pre-notch along the line of symmetry at the specimen's edge and oriented along the loading direction, subjected to a three-point bending load, as shown in Fig. 3. Considering the specimen's geometry, tensile crack (model I) is induced in SCB test.

Chong et al. [24] proposed a formula for determining $K_{I}$ by using both the strain energy release rate method and the elliptical displacement approach, which is given by

$$
K_{I}=\frac{P \sqrt{\pi a}}{D \delta} Y_{K}
$$

where $P$ is the applied force, $D$ is the diameter of the SCB specimen and $\delta$ is the thickness. $Y_{K}$ is the dimensionless stress intensity factor as a function of the dimensionless crack length, a/D. $Y_{K}$ can be approximated by a third order polynomial as follows 


$$
Y_{K}=4.47+7.4 \frac{a}{D}-106\left(\frac{a}{D}\right)^{2}+433.3\left(\frac{a}{D}\right)^{3}
$$

For $0.25 \leq a / D \leq 0.35$ and $S / D=0.4$ with $2 S$ is the loading span.

For the stress state near the crack tip, the criterion of crack propagation can be given in the following form: $\mathrm{K}_{\mathrm{I}} \leq \mathrm{K}_{\mathrm{IC}}$, which is extremely convenient for applications. Where $K_{I}$ is the stress intensity factor, and $K_{I C}$ is the static fracture toughness. We notice that $K$ is not a local but an integral characteristic, depending on the energetic state of the whole construction. Thus, in the problem of static loading there are two fracture criteria: $\mathrm{P} \leq \mathrm{P}_{\mathrm{C}}$ for defectless media and $\mathrm{K}_{\mathrm{I}} \leq \mathrm{K}_{\mathrm{IC}}$ for crack domains. In both cases, we are dealing with certain external stress attaining the given critical value, whereupon, according to the theory, a fracture occurs instantaneously. Therefore, fracture toughness $K_{I C}$ under mode I condition can be possible calculated from the stress intensity factor solutions, is given by

$$
K_{I C}=\frac{P_{C} \sqrt{\pi a}}{D \delta} Y_{K}
$$

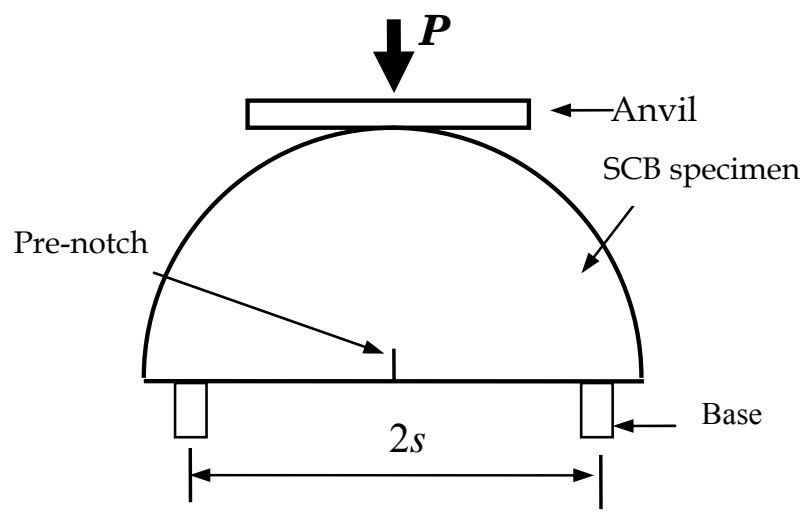

Fig. 3. Geometry of semi-circular bend test

\subsection{Punch loading tests}

PBX is increasingly used in decreased sensitivity munitions at low strain rate. Mechanical stimuli may affect the safe working life of explosives. In order to understand the mechanisms that lead to reaction or detonation, it is important to know the mechanical behavior of PBX. The punch loading test was proposed by Prandtl. In this method, a rigid object slowly penetrates the material to study the fracture process and failure mechanisms [25]. In literature [25, 26], the flat punch loading test has been carried out on a PBX mock material. In our work, two punch loading experimental patterns, including the flat punch and wedge-shaped punch test, were used to study the fracture behavior of PBX simulant. In this paper, only the flat punch loading results are shown providing some further insights into PBX fracture. The length, width and height of a specimen are $20 \mathrm{~mm}, 8 \mathrm{~mm}$ and $6 \mathrm{~mm}$ respectively. Contact surface size is $5 \mathrm{~mm} \times 5 \mathrm{~mm}$ for punch, which was used to impact the top of the specimen at a rate of $1.8 \mathrm{~mm} /$ minute. 


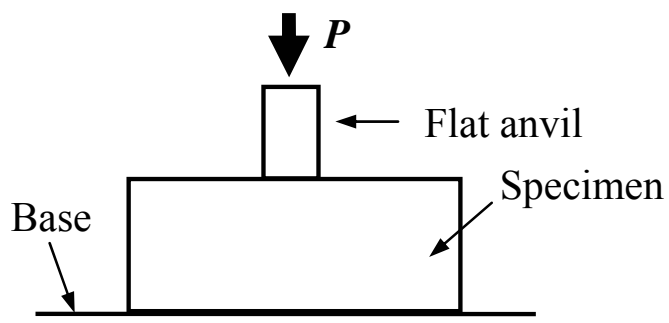

Fig. 4. Schematic diagram of a flat punch loading test

\section{Results and discussion}

\subsection{Brazilian test}

Following, a disc specimen with $20 \mathrm{~mm}$ diameter and $8 \mathrm{~mm}$ thickness was diametrically compressive loaded in a material test system (MTS). The loading velocity is 0.05 $\mathrm{mm} /$ minute. Images of evolving movement of the speckle pattern were recorded by using a CCD camera at a frame rate of 5 frames per-second, with a high resolution of $1624 \times 1236$ pixels ${ }^{2}$ in each image. During the test, the applied compressive load $P$ was normalized by the product of the specimen initial thickness $\delta$ and the radius $\mathrm{R}$ of the disc specimen, and the diameter change $\Delta$ along loading axis was normalized by the specimen initial diameter $D$. Fig. 5 shows the resulting relationship of the applied compressive load $(P /(\delta R))$ versus the displacement $(\Delta / D)$. It is obvious that the applied force firstly linearly increases with the deformation increases. The force reaches a maximum, and then rapidly decreases.

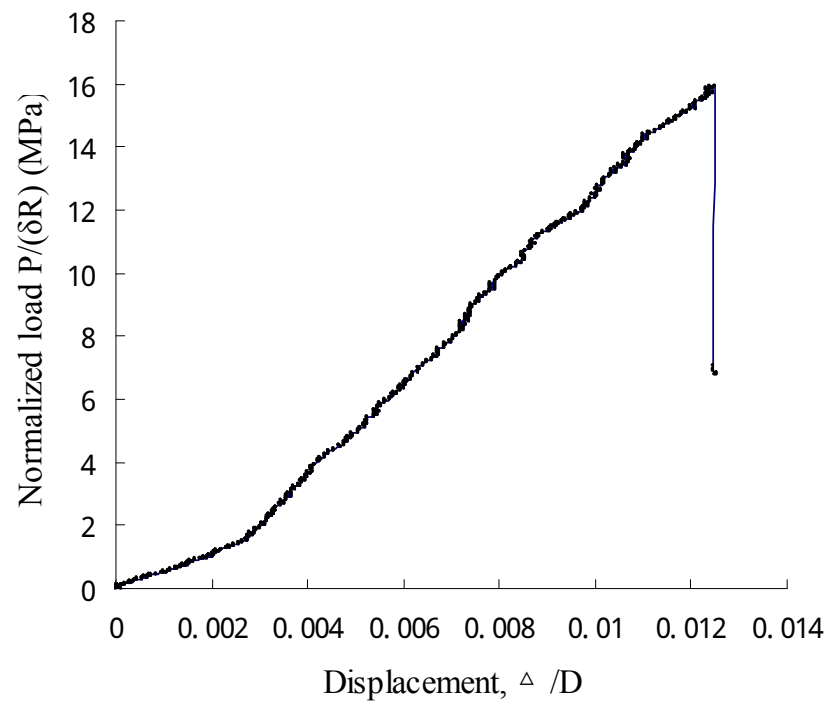

Fig. 5. Relationship of the applied compressive load and displacement

It is believed that the disc specimen fractures at the maximum load, indicating a brittle failure behavior. The tensile strength was calculated using Equation 4 from the applied 
force, and the magnitude of tensile failure stress is about $5.07 \mathrm{MPa}$. Fig. 6 shows the strain field distribution which corresponds to the state that the fracture of specimen occurs. The image shows how the strain localizes along the loading axis, indicting the possible crack developing route. The largest strain occurred near the contact points of specimen and anvils, which is caused by the stress concentration, and premature failure occurs under shear stress action.

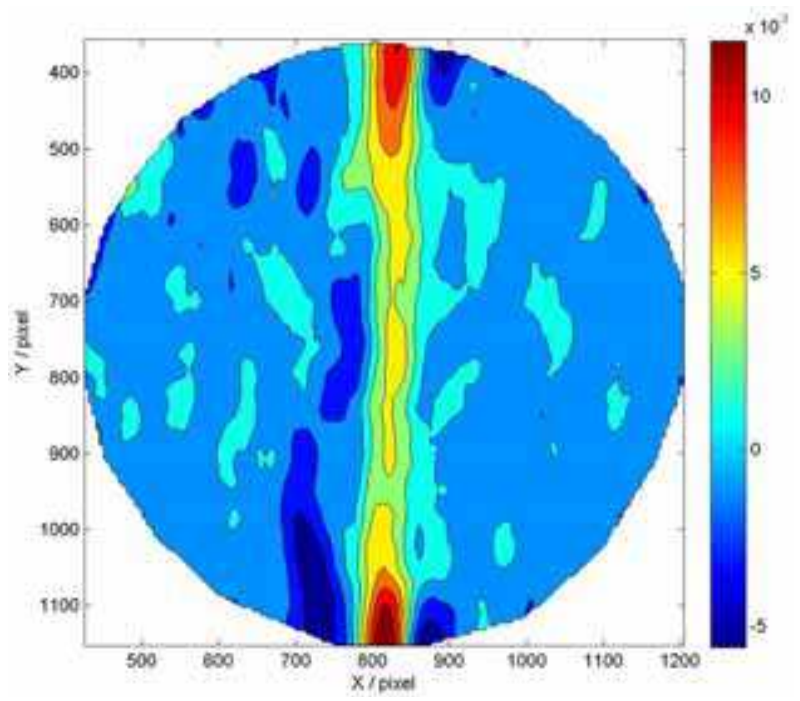

Fig. 6. Strain $\left(\varepsilon_{\mathrm{x}}\right)$ distribution

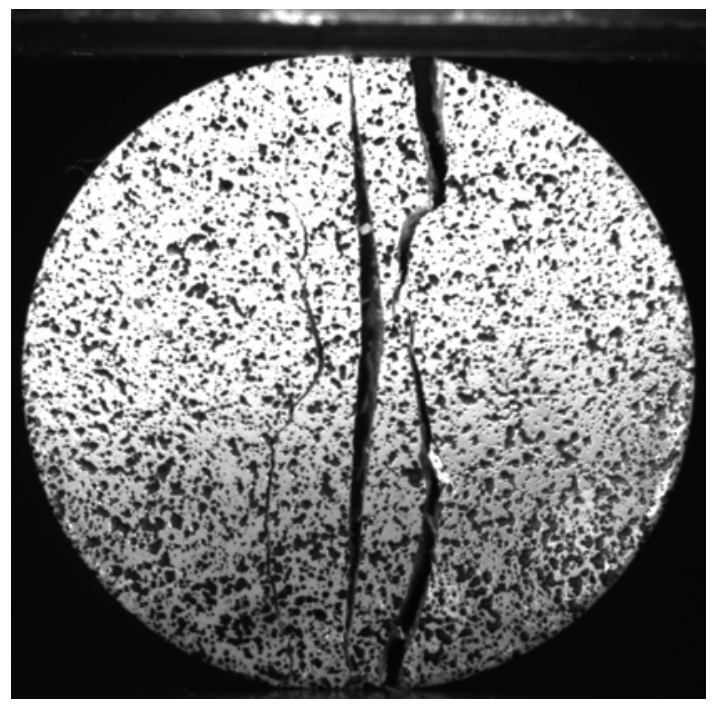

Fig. 7. Fracture morphology of PBX 
The strain field calculated from the DIC can demonstrate the material damage underneath the specimen surface even though there were no differences between the surface topographies at different loading state for the specimen prior to total failure. Fig. 7 shows the typical fracture morphology of specimen in Brazilian test. The tensile failure path is along the loading axis and the crack opening displacement in the disc specimen center is largest. The principle crack initiated at the specimen center and evolved upward and downward along the loading line. Moreover, two sub-cracks occurred in specimen, which was due to shear stress at the contacts between specimen and anvils. The right sub-crack occurred and propagated into the specimen, but not run through.

\subsection{Compression tests}

Quasi-static compressive loads were performed on simulant specimens. A series of block specimens with aspect ratio of 1.8, 2.0 and 2.3 were used to study the different failure mechanisms. In order to discuss the deformation and fracture behavior of specimens under compressive load, the captured speckle images were computed by the DIC.
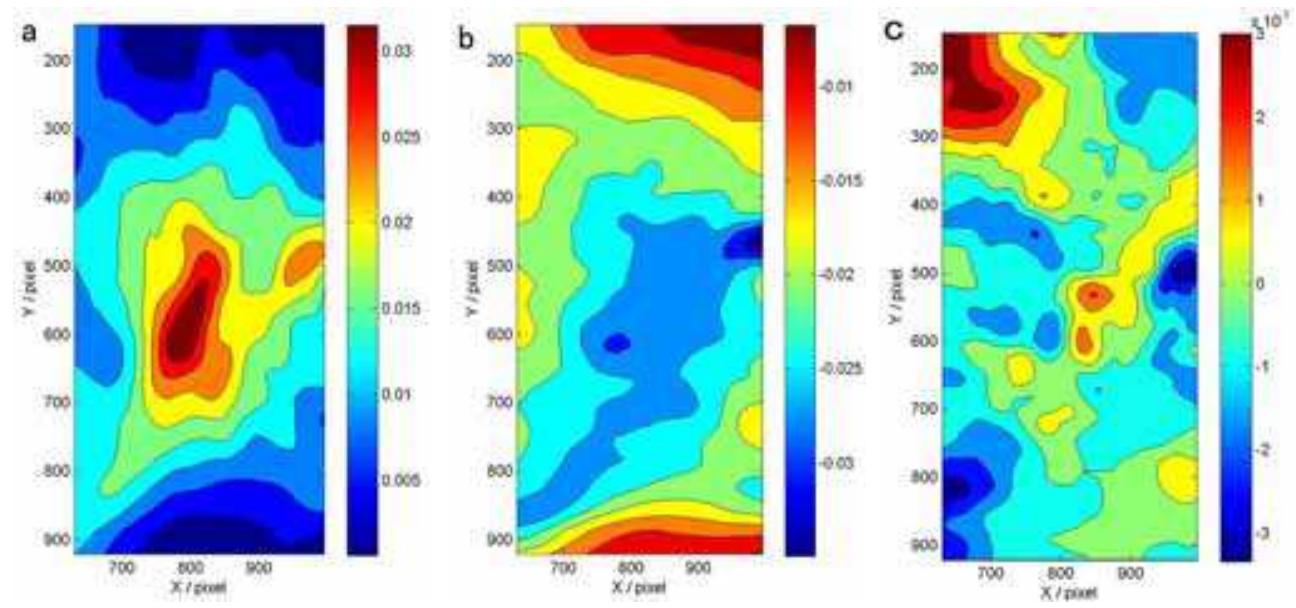

Fig. 8. Strain components distribution. a) Extensive strain $\left.\left(\varepsilon_{\mathrm{x}}\right), \mathrm{b}\right)$ Compressive strain $\left(\varepsilon_{\mathrm{y}}\right)$, and c) Shear strain

For a block specimen with size of $20 \mathrm{~mm}$ height by $10 \mathrm{~mm}$ width by $10 \mathrm{~mm}$ thickness, a series of random speckle patterns were captured before and after load. Fig. 8 illustrates the computed strain field distribution for the block specimen just prior to total failure under compressive load. In Fig. 8a, it is obvious that a concentrated strain band localizes in an area along the load axis near the center of the specimen. Meanwhile, a localized shear strain band concentrated in the area near the diagonal line, as shown in Fig. 8c. From these strain maps, it can be seen that the extension strain is larger than the compression and shear strain in the center, demonstrating that the macroscopic fracture mode of the specimen is dominant caused by extension and shear action when under external force. The whole vector field of displacement distribution gives a quantitative measurement, as shown in Fig. 9. Two wedges of matters can be seen driven downward and upward into the material with shear regions clear visible, and the central materials moved to the left and right approximately 
perpendicular to the loading axis. The vectors are scaled and can be used as a quantitative measurement. The result gives a clear indication of the failure mechanisms in the specimen more clearly than by observation.

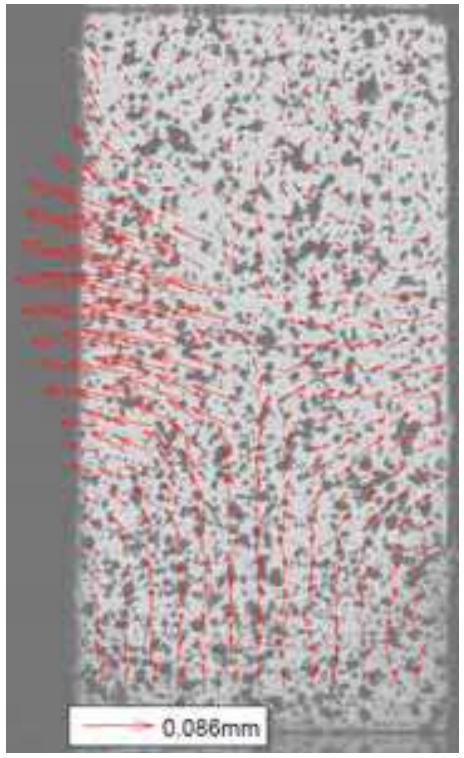

Fig. 9. Displacement vector with aspect ratio of 2.0

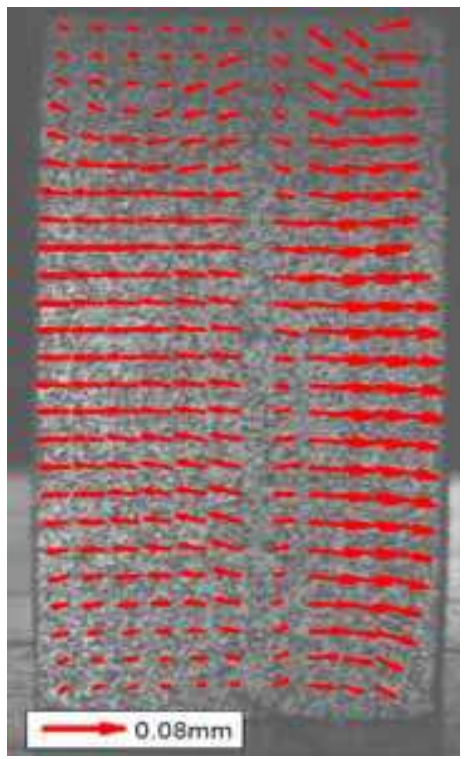

Fig. 10. Displacement vector with aspect ratio of 2.3 
Fig. 10 shows the displacement vector pattern under a compressive force calculated by using the DIC. Here, it can be seen that the materials flow to the right and left approximately along the central loading axis. Meanwhile, a tensile crack can be seen on the specimen surface. Fig.s 11a-c show the whole strain field distribution of a specimen with the size of $10 \times 10 \times 23 \mathrm{~mm}^{3}$ under compressive load. In Fig. 10a, it is obvious that a concentrated extensile strain band localizes along the load axis and extends from the top of specimen to the bottom. The maximum strain value is approximately 0.06 in tensile stress field near the center of the specimen. While the compressive and shear strain values are very small, the maximum value is less than 0.01 , as shown in Fig.s $11 \mathrm{~b}$ and c. Comparing this to Fig. 8,
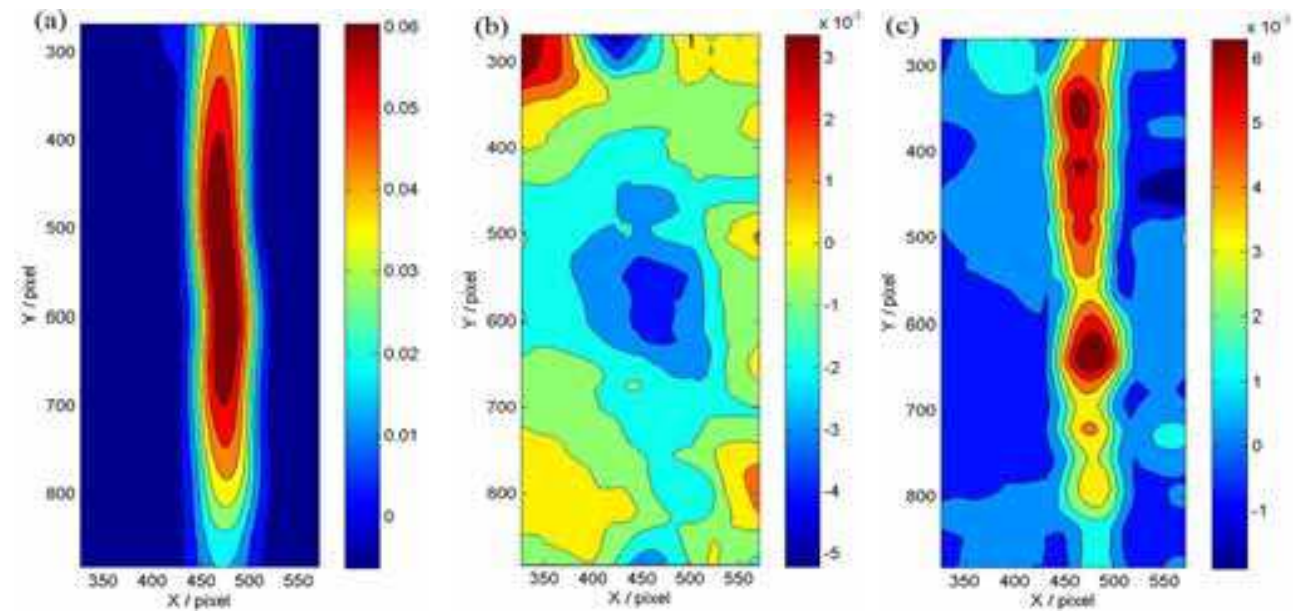

Fig. 11. Strain components distribution. a) Extensive strain $\left.\left(\varepsilon_{\mathrm{x}}\right), \mathrm{b}\right)$ Compression strain $\left(\varepsilon_{\mathrm{y}}\right)$, and c) Shear strain
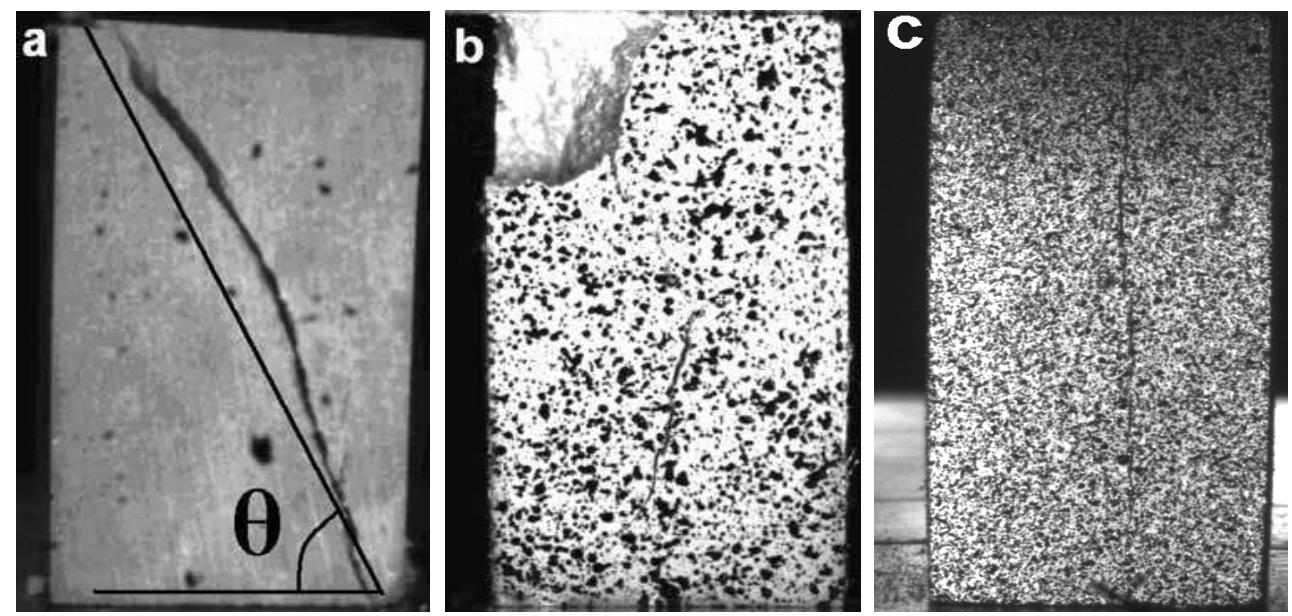

Fig. 12. Fracture morphology of specimens. (With different aspect ratio. a) 1.8; b) 2.0; c) 2.3) 
results indicate that the fracture mechanism of block specimens under compressive loading is different significantly with aspect ratio changes. It is believed that the macroscopic fracture of specimen with aspect ratio of 2.3 is dominant caused by extension action.

The fracture monographs of specimen are evidently different shown in Fig. 12. Fig. 12a shows the post-failure specimen photography. It can be seen that the fracture path is nearly along the diagonal line, which was caused by shear stress action when subjected to compressive loads. With aspect ratio increased, the fracture mode is changed. Fig. 12b shows the fracture morphology of PBX simulation material with aspect ratio of 2.0. Fracture surface can be seen obviously at the top left corner, the main crack is running from the upper left corner to the lower left corner, and in the center of the specimen it is running along the vertical axis. Result shows the fracture mode is mainly caused by the extension and shear action. When the aspect ratio is up to a critical value such that the shear action disappeared, as shown in Fig. 12c, a single crack can be seen which is caused by the extension stress action, and the failure plane is parallel to the loading axis. Fracture photographs are in agreement with the results predicted from the strain fields.

Displacement and strain fields obtained in the experiments have examined the failure mechanisms of block specimen under compression load, to provide explanations for the observed failure behavior. The compression experiments carried out at an aspect ratio of 1.8 gave an ultimate compressive engineering stress of about 50.21 MPa. Based on the MohrCoulomb failure law [27], a quasi-static compression data has been obtained on a cylindrical specimen PBS9501[28], the shear stress $\tau$ can be given by $\tau=\mu \sigma_{n}+c$, where $\sigma_{n}$ is the normal stress acting on failure plane, $c$ is the cohesion and $\mu$ is the friction coefficient. The angle of internal friction of the material $\varphi$ is relative to the friction coefficient through the relationship $\mu=\tan \varphi$ and can be calculated by $\theta=\pi / 4+\varphi / 2$. Where $\theta$ is the angle made between the failure plane normal and the loading axis. From Fig. 12 (a) the value $\theta$ is approximately $61^{\circ}$, then the friction angle can be calculated and the value is about $32^{\circ}$. Given this information, a value for the coefficient of cohesion can be calculated to be about $13.47 \mathrm{MPa}$. Additionally, the tensile strength is approximately $14.93 \mathrm{MPa}$. Results can be conductive to understand the material fracture properties.

\subsection{Semi-circular bending tests}

Semi-circular specimens were pre-notched with a $0.2 \mathrm{~mm}$ thickness steel blade, the initial pre-notch of $1.0 \mathrm{~mm}$ length was along the line of symmetry at the specimen edge and oriented along the compression direction. Pre-notched specimens were sprayed with mists of black and white paints alternatively to create the random speckle patterns. A CCD camera was used to record decorated random speckles movement in situ. In order to investigate the fracture mechanism under mechanical loading, speckle images were digital processed using the DIC. The displacement and strain fields were calculated.

Fig. 13 shows the extensive strain field maps at two loading steps of $\mathrm{P}=105 \mathrm{~N}$ and $\mathrm{P}=479 \mathrm{~N}$ respectively. In Fig. 13a, it can be noted that a concentrated tensile strain band localizes in the vicinity of tip of the prefabricated notch. Meanwhile, it can also be noted that a localized strain presents in an area near the anvil, which is caused by the point-contact between anvil and specimen. As external force applied further, the localized extensive strain is evolving continuously along the pre-notch orientation, see Fig. 13b. It is believed that during this process the initial damages underneath the specimen surface may be activated and some new damages will generate. Results indicate that a possible fracture path will follow the concentrated strain band and the specimen will break into two parts eventually. 


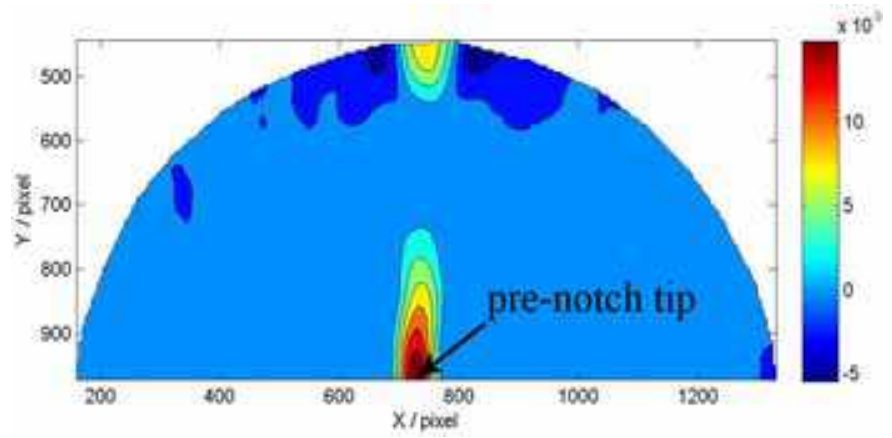

(a) $\mathrm{P}=105 \mathrm{~N}$

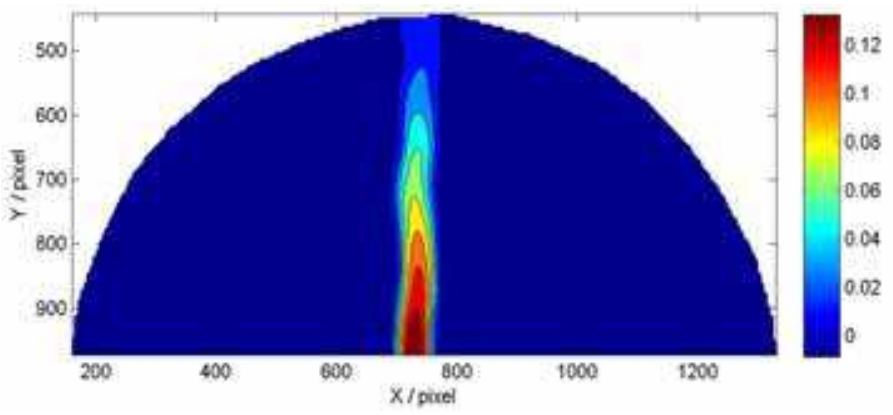

(b) $\mathrm{P}=479 \mathrm{~N}$

Fig. 13. Tensile strain field $\left(\varepsilon_{x}\right)$ of SCB specimen at different load

Fig. 14 shows the vector distribution of displacement under a tensile stress calculated by the DIC. The vector arrows are scaled and can act as a quantitative measurement for discussing the failure behavior of semicircular specimen under compression loading. In Fig. 14, a single

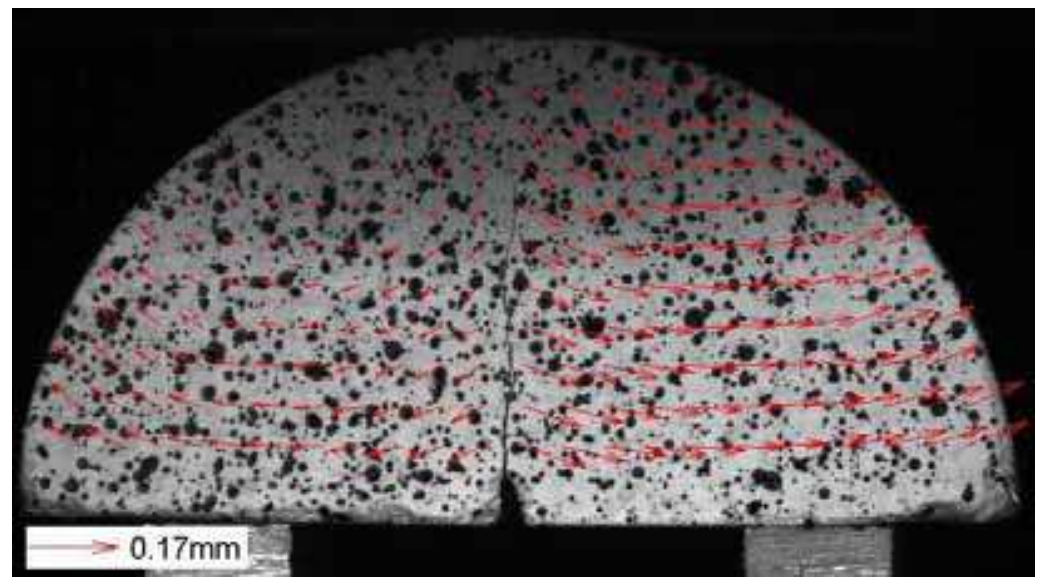

Fig. 14. Vector field of displacement for a post-failure SCB specimen 
macroscopic crack can be observed on the specimen surface, this crack is just in the line with the orientation of pre-notch. Typically, it is obvious that the materials left and right of the failure path moved horizontal just perpendicular to the load axis. Result is in agreement with the prediction from the whole strain field. All the results indicate that the material is suffering from large extension stress under compressive loading.

Cracking is the most dominate mechanical failure mechanism in high explosives and could affect the mechanical performance and detonation of weapon systems. However, it is a challenge that the direct observation and quantitative measurement of the deformation field associated with the formation and extension of microcracks, because cracks are hard directly observed until they have grown large enough. Nevertheless, in recent years, a technique has been developed to quantitatively describe the initiation and propagation of cracks in explosive materials [29]. In DIC calculation, the correlation coefficient $C$ is a function of two random speckle images captured before and after a deformation. When two small images match each other, the correlation coefficient reaches a minimum. However, when damage or cracks develop in the small region during deformation, the value of the coefficient $C$ becomes bigger than other regions where no damage or cracks are present. In this work, based on the above discussion, we use the correlation coefficient to quantify the location and extent of cracks in SCB specimen.

Fig. 15 shows the contour plot of normalized correlation coefficient at four loading states. For PBX specimen, at moment A, the normalized correlation coefficient over the entire specimen surface is a constant, the magnitude of coefficient $C$ is approximate 0 , indicating that the two speckle images match each other very well, and no damage formed. In the subsequent moments, $\mathrm{B}, \mathrm{C}$ and $\mathrm{D}$, in some regions within the specimen surface the normalized correlation coefficient becomes bigger than other regions. In moment $\mathrm{B}$, the small cracked region formed around the preset crack, and at the next moments $\mathrm{C}$ and $\mathrm{D}$, the cracked region grows larger. Specially, at moment D, a single dominant crack is generated along the orientation of preset crack.

In addition, a set of SCB tests were carried out to determine the fracture toughness. Fig. 16 shows the typical relationship curve of load $P$ and crack opening displacement $V$, in which the crack opening displacement was determined using DIC technique. Follow ASTM standard procedure E399, increment of crack extension was established by a 5 percent deviation from the linear portion of the record. A secant line through the origin of the test record with slope $(\mathrm{P} / \mathrm{q})=0.95(\mathrm{P} / \mathrm{q})_{0}$ where $(\mathrm{P} / \mathrm{q})_{0}$ was the slope of the tangent line 1 to initial linear part of the record was drawn. Load $\mathrm{P}_{\mathrm{q}}$ was defined at the point of intersection of the secant line 2 and the curve. If $P_{m}$ is taken as the maximum load achieved, the ratio $\mathrm{P}_{\mathrm{m}} / \mathrm{P}_{\mathrm{q}}$ is found to be about 1.05 in most cases, but less than 1.1 in all tests satisfying the requirements for plane stain fracture toughness measurement. In this work, the critical failure load is determined by $\mathrm{P}_{\mathrm{m}} / \mathrm{P}_{\mathrm{q}}=1.05$, given these information, combining Equations 6 and 7, the fracture toughness $K_{I C}$ of SCB specimens are given in Table 1 . The fifth column gives the critical failure force determined by Equation $\mathrm{P}_{\mathrm{m}} / \mathrm{P}_{\mathrm{q}}=1.05$, the last column shows the plane strain fracture toughness of four semicircular specimens. Results show that the $\mathrm{K}_{\mathrm{IC}}$ value is approximately $0.50 \pm 0.02 \mathrm{MPa} \mathrm{m}^{1 / 2}$. Unfortunately, the study on the fracture toughness of real PBX materials is very rare in literature at present due to difficulties in experiments, so the method described in this paper may be provide some further insights into this issues. 


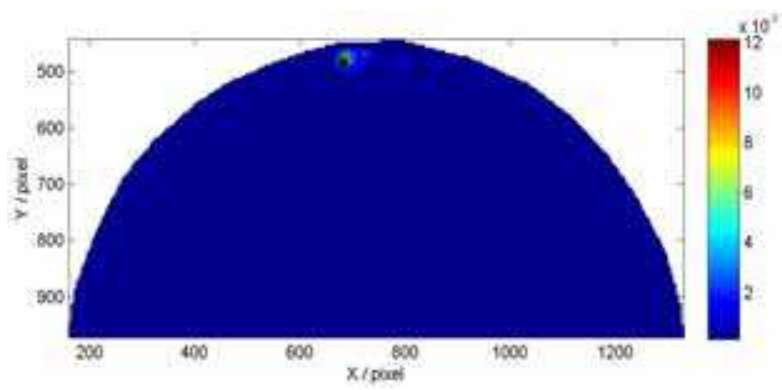

(a) $P=360 \mathrm{~N}$

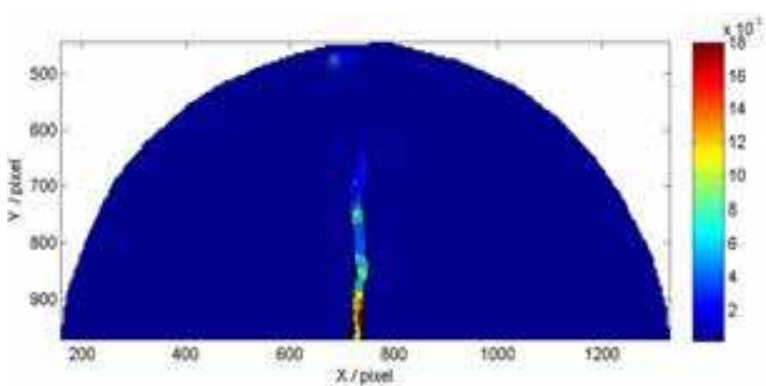

(b) $\mathrm{P}=385 \mathrm{~N}$

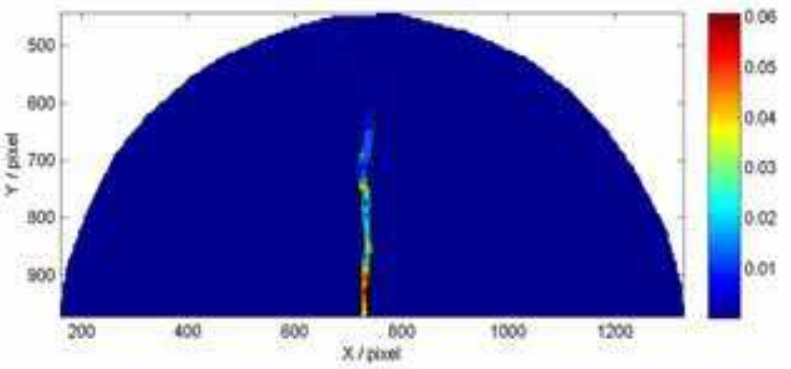

(c) $\mathrm{P}=410 \mathrm{~N}$

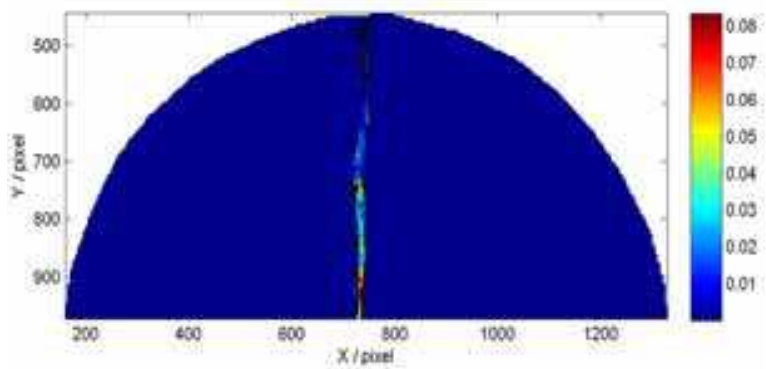

(d) $\mathrm{P}=435 \mathrm{~N}$

Fig. 15. Contour plot of normalized correlation coefficient at four selected moments in SCB test 


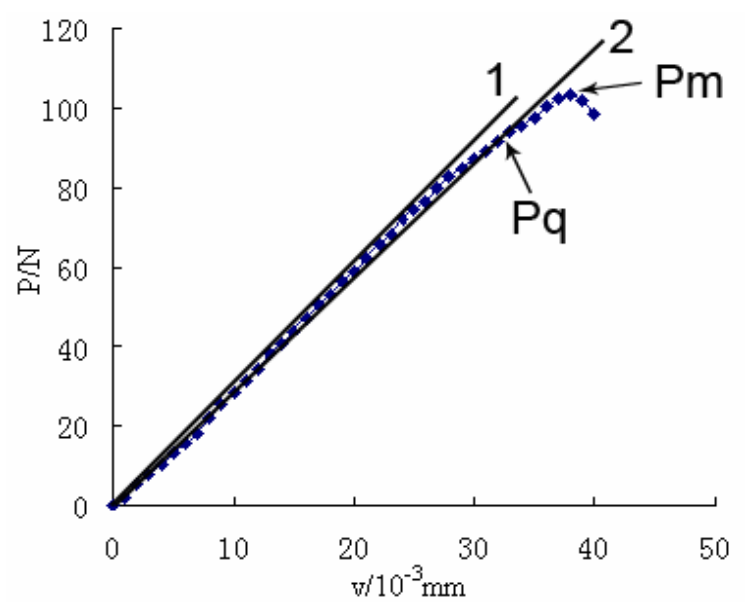

Fig. 16. Relationship of load versus crack opening displacement

\begin{tabular}{cccccc}
\hline$a / \mathrm{mm}$ & $\mathrm{D} / \mathrm{mm}$ & $\mathrm{B} / \mathrm{mm}$ & $\mathrm{P}_{\mathrm{m}} / \mathrm{N}$ & $\mathrm{P}_{\mathrm{q}} / \mathrm{N}$ & $\mathrm{K}_{\mathrm{IC}} / \mathrm{MPa}^{1 / 2}$ \\
\hline 4.9 & 20 & 9 & 119.58 & 113.89 & 0.49 \\
5 & 20 & 9 & 116.27 & 110.73 & 0.50 \\
5 & 20 & 9 & 122.18 & 116.36 & 0.52 \\
5.1 & 20 & 9 & 107.55 & 102.43 & 0.48 \\
\hline
\end{tabular}

Table 1. Specimen dimensional requirements for fracture toughness measurement

\subsection{Punch loading test}

Fig. 17 shows the displacement vector field of the specimen under the flat punch loading test prior to failure. Viscoelastic-plastic flow occurred in the specimen during punch penetration. The direction and magnitude of the plastic flow are represented by vector arrows which represent the relative degree of the displacement from the beginning of the experiment. The displacement quivers plot shown, as a quantitative measurement, gives a clear indication of the failure mechanisms in the specimen than visual observation. It is obvious that a triangular 'dead zone' has been completely formed in the specimen. In 'dead zone', the matter moves downward with the punch itself at the same velocity $V$, if not, the matter flows from the side of dead zone towards to the free surface at the velocity of $0.731 \mathrm{~V}$. Fig. 18 illustrates the definite contour of tensile strain in horizontal direction when compression loading was applied to 6 seconds, just for the specimen prior to fracturing. This Fig. clearly shows the strains distribution on the specimen surface. It can be seen that strain contours are mainly concentrated underneath the flat punch and the maximum tensile strain is about 0.02. So it is believed that microcracks occur underneath the specimen surface, propagate and coalescence a large macrocrack, and finally induce cleavage rupture of the specimen with increasing of external force. It is also possible to generate full shear strain fields. As shown in Fig. 19, the strain concentration slip bands just localized underneath the punch and on the sides of the dead zone, where the highest shear strain rates and shear stresses produce and could cause fracture. Further SEM examination of this region can validate the shear fracture models. 


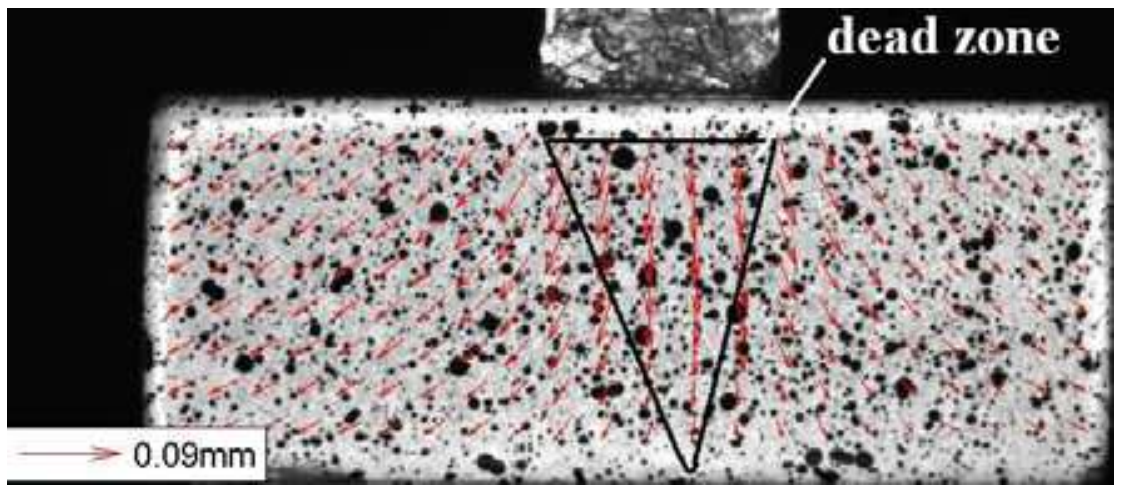

Fig. 17. Displacement vector field of the specimen under flat punch loading test

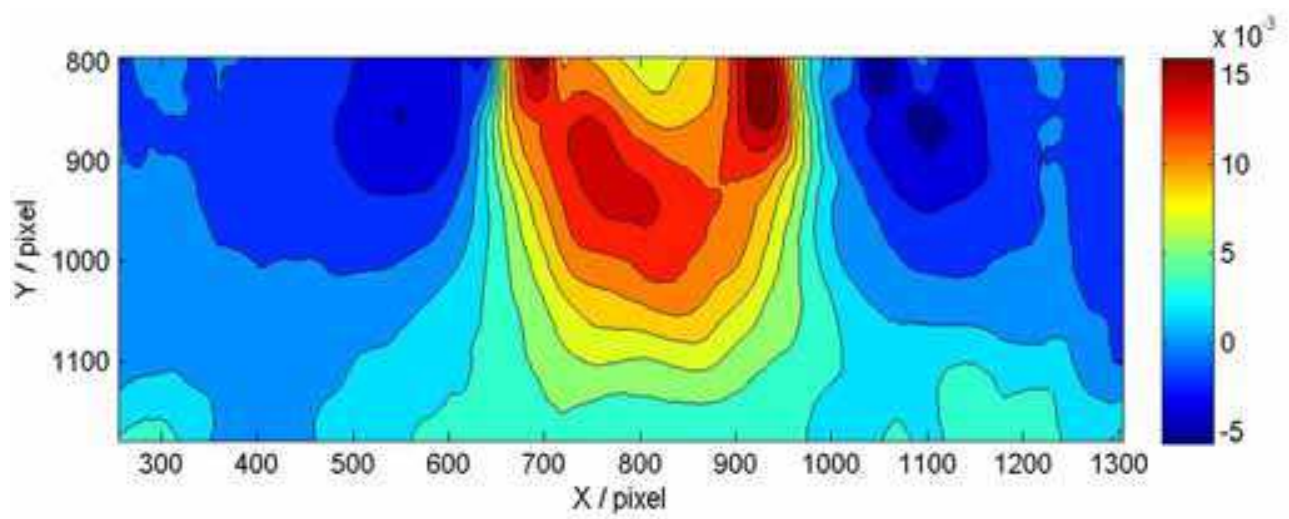

Fig. 18. Tensile strain field $\left(\varepsilon_{y}\right)$ from a flat punch loading results prior to failure

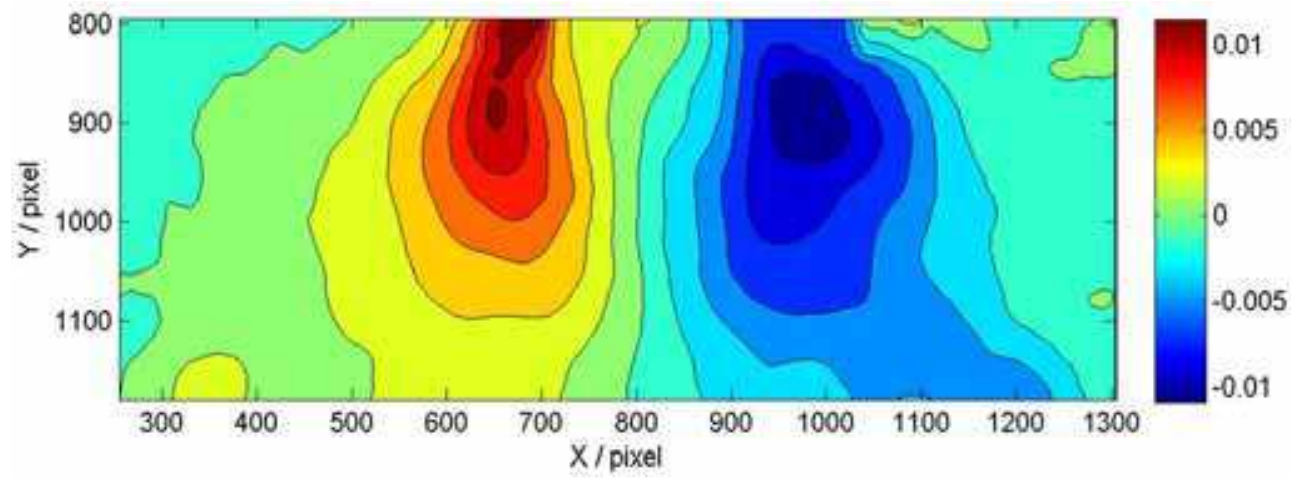

Fig. 19. Shear strain field from a flat punch loading result 


\subsection{Microstructure measurement}

SEM was used to examine the microstructure of PBX. The observed surface should be polished before the testing. The experimental results show that the initial damages, such as microscopic voids may be caused by the small filler particles flowed and reset between large filler particles during hot compacting process and microcracks can be observed. Careful examination can see that deformed twinning occurred on the single particle surface. It's known that twinning allows particles to accommodate large strains without fracture, but fractures can develop through the particles with increasing of the external force, it is considered that the twin is forming a step at the surface that acts as a stress concentrator [30].

Real time microscopic examination reveals that different forms of failure including interfacial debonding and particle fracture can be observed. The failure generally starts at many independent sites, usually around the boundaries of the large filler particles before linking up into larger cracks, and finally induce cleavage rupture of the specimens. The initial damage, such as debonding generated during the pressing, is the origin of failure. Particle fracture was very rare, but may appear due to the orientation of a long crystal face lying perpendicular to an advancing crack path. Fig. 20 shows the results of real time microscopic examination of PBX simulation material in Brazilian test. Results show that cracks are extending along the boundaries of larger filler particles.

Real time SEM examination of a block specimen shows that different fracture modes can be seen. Fig. 21 shows that interfacial debonding is the dominate failure mode in compression test. In particular, the crack path mainly follows the boundaries of the filler particles. However, particle fractures do occur when the particle orientation impedes the crack growing path even this failure rare occurrences, see particle K. Moreover, microscopic cracks (indicated by arrows in Fig. 21) occurred within the filler particles, see particles $M$ and $\mathrm{N}$, which may be caused by initial damage activated and evolved under external force. The microcracks may coalescence and induce particle breakage finally. Therefore, both the interfacial debonding and the particle breakage indicate that the transgranular cracking and intergranular cracking are the significant failure modes.

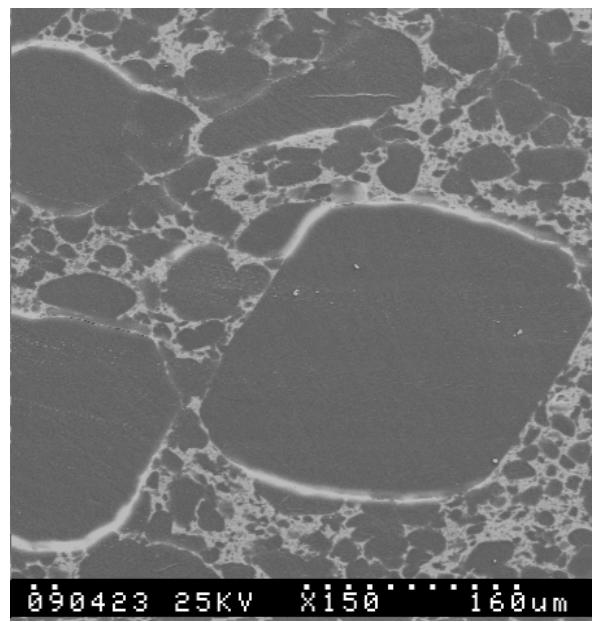

Fig. 20. Micrograph of a specimen in Brazilian test 


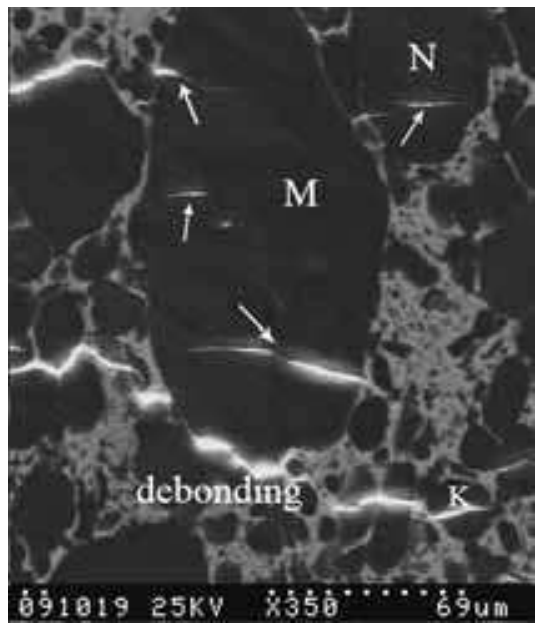

Fig. 21. Micrograph of a specimen in compression

The non-uniform strain field distribution in PBX simulant specimens calculated by the DIC offers basic information and can well predict the damage when specimen was loaded by compression. Moreover, as shown in this work, the deformation field obtained through DIC is also possible to reveal the strain singularity in particle-based composites and to predict the growing path of the cracks during the fracture process. A SCB specimen with a size of 20 $\mathrm{mm}$ in diameter and $10 \mathrm{~mm}$ in thickness was machined from a disc specimen, and an edge pre-notch with $0.9 \mathrm{~mm}$ length and $0.2 \mathrm{~mm}$ width was fabricated in the specimen perpendicular to the load direction, as shown in Fig. 22.

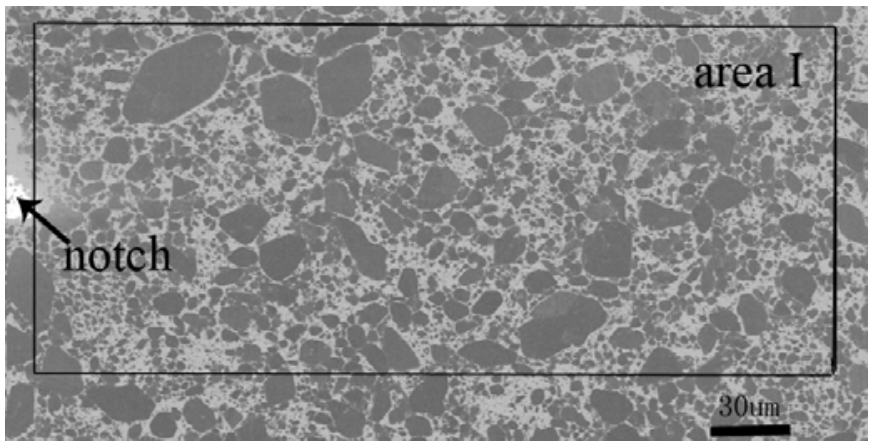

Fig. 22. Micrograph of a SCB specimen

The semicircular disc specimen was compressed by a flat steel anvil installed in SEM chamber. The near region (rectangular area I shown in Fig. 22) around the tip of the prefabricated crack was magnified by the SEM to real time observe the surface topography and to record the images during the quasi-static loading. For each loading step with a force increment about $\Delta \mathrm{P}=50 \mathrm{~N}$, the digital surface image was analyzed by DIC to match with the initial image recorded before deformation so as to obtain the displacement field and strains. This can show the deformation history by load steps to reveal the strain locality and to 
predict the crack possible growing path. Fig. 23 illustrates the strain contours of a specimen in semicircular bend test at three loading steps of $P=150 \mathrm{~N}, P=250 \mathrm{~N}$ and $\mathrm{P}=400 \mathrm{~N}$, respectively. The extension strain field is not uniform. It can be noted that the maximum contours are concentrated around the tip of prefabricated crack, and it can also be seen that the localized strain is propagating and evolving along the pre-notch direction with external load increasing, so the primary failure route is following prefabricated crack orientation.

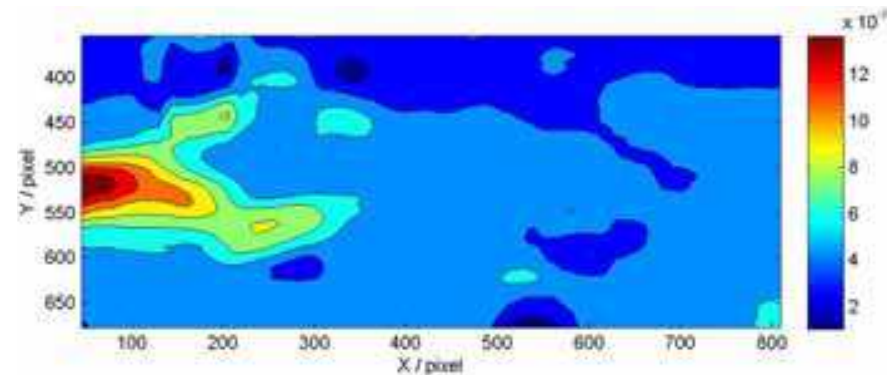

(a) $\mathrm{P}=150 \mathrm{~N}$

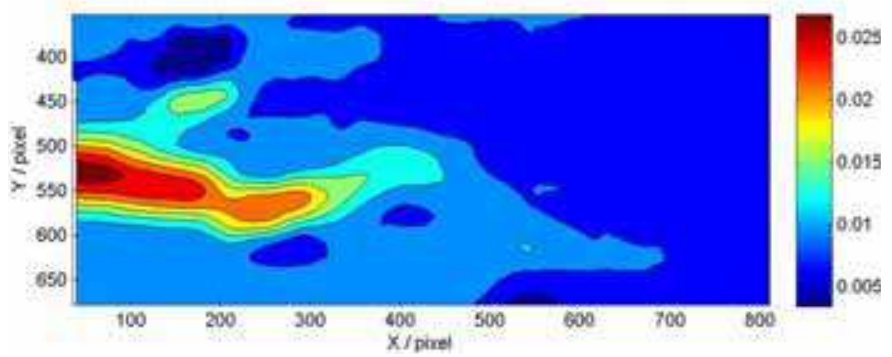

(b) $\mathrm{P}=250 \mathrm{~N}$

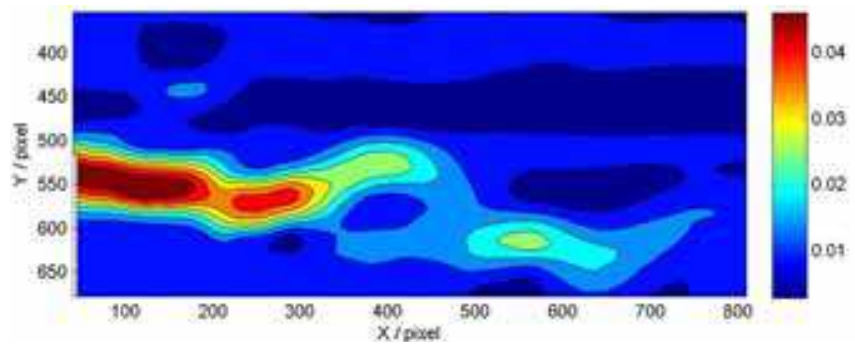

(c) $\mathrm{P}=400 \mathrm{~N}$

Fig. 23. Strain contours of a specimen at different loads in SCB test

SEM was taken to examine the damage occurred in simulant materials. Fig. 24 indicates the SEM image of the fracture surface of a simulant specimen. The flat fracture morphology of specimen can be seen, demonstrating that the filler particles experienced transgranular fracture. Some microcracks can be seen on the large particles indicated by arrows, and interfacial debonding can be noted. 


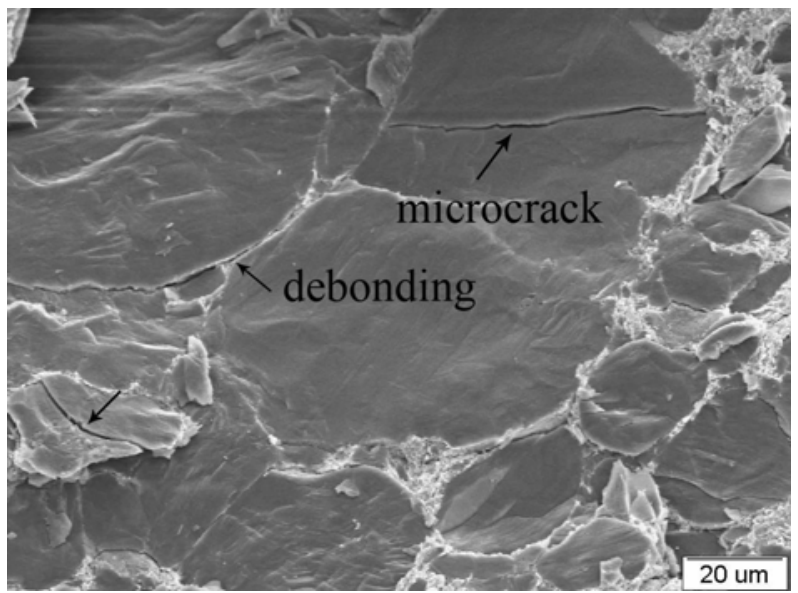

Fig. 24. Fracture morphology of PBX in Brazilian test

Fig. 25 shows the SEM image of the block specimen fracture surface under compression loading. It can be seen that the particles experienced fragmentation. A large number of smaller particles formed, which indicates the compression induces a lot of filler particle crushing. Typically, Fig. 25 clear reveals the presence of brittle particle and cleavage fracture, and the particle $Q$ dislocation fracture (indicated by arrow) is obvious caused by particle to particle contact. It is believable that the particle fractures are mainly associated with particle to particle contact due to an extremely high density of filler particles in simulation material. Fig. 26 shows an image of shear slips in the hard particle directly to the side of intruding punch, demonstrating that large shear stresses occurred in this region of the specimen during punch penetration.

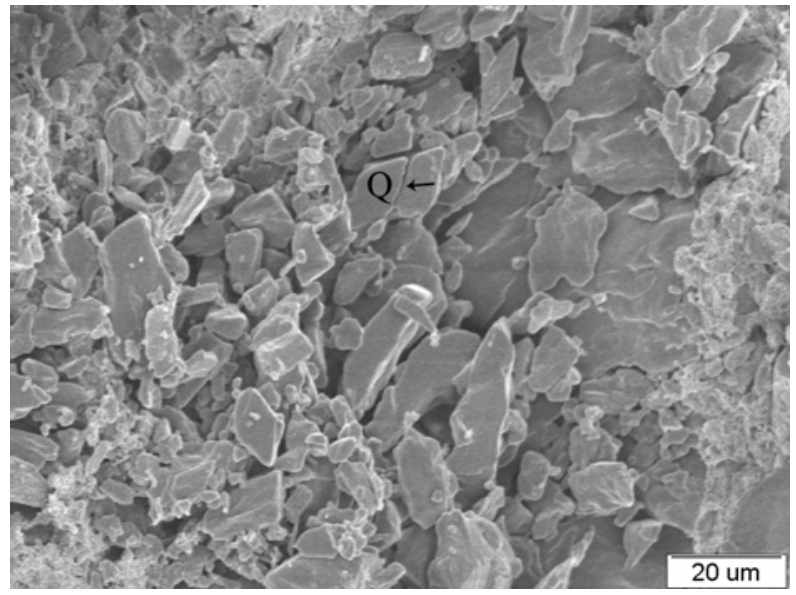

Fig. 25. Fracture morphology of PBX in compression

Previous studies in the literatures [4, 6, 31-32] shown that failure tends to start around the boundaries of large filler particles. Results show that the predominant failure mode of PBX 
is interfacial debonding between explosive particles and binder under extension action. While further examples have been presented in this paper, the failure path in PBX simulant appears to follow unexpected routes. Our studies of PBX simulant under tensile stress field suggest that the transgranular cracking is the dominant fracture mode. It should be remembered that specimens are three-dimensional materials even only the exposed surface can be observed. Consequently, particles just below the observed surface may influence the measured behavior.

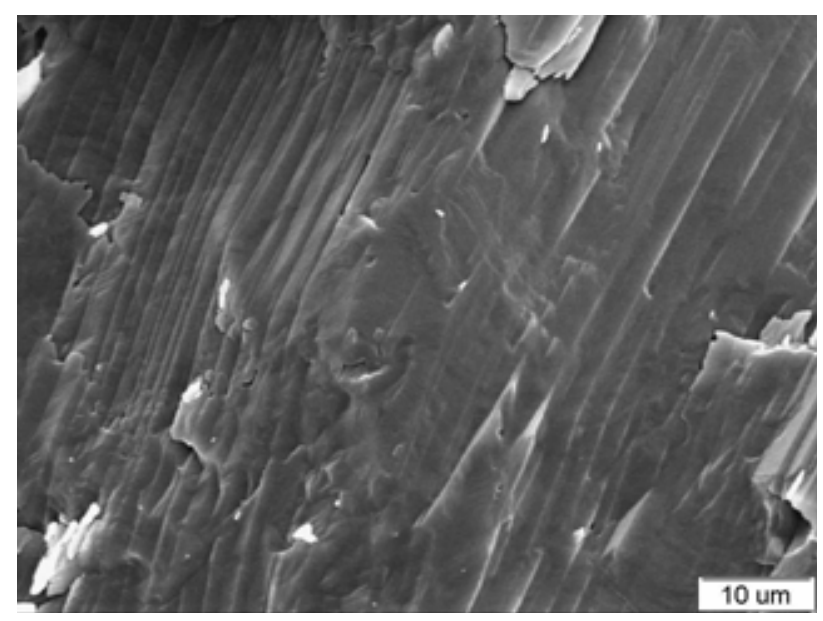

Fig. 26. Shear slips in a particle

\section{Conclusions}

As PBX systems becoming more widely used, the understanding of the damage and fracture mechanisms responsible for safety working life evolution is important. As discussed, DIC is an optical full-field measurement technique. Even though no information can be generated to investigate the internal material motion, the deformation and fracture behavior of PBX simulants can be studied according to the full strain field and displacement vector plots on specimen's surface. More important, the digital correlation processing of SEM images can provide the non-uniform deformation information in PBX simulants, demonstrating the microscopic damage evolution and predicting possible failure routes in specimen. In addition, the advantage of DIC described here is the ability to make tensile stress/strain measurements. Moreover, based on Mohr-Coulomb failure criteria, the fracture parameters, such as cohesion and friction angle etc, can be calculated. In addition, the fracture toughness can be determined by using the SCB test. The results are contributing to understand the fracture mechanical properties of specimens under compressive loading.

PBX simulant is a highly filled composite consists of up to $95 \%$ by weight particles coated by binder. Therefore, the coverage degree is less than $100 \%$. Microstructures of PBX simulant were observed by using an SEM. Real time microstructure examinations show that decohesive failure of interface between particles and binder is the dominant fracture mode due to incomplete interfacial cohesion. In addition, particle cleavage fracture can also be seen evidently under the compression and shear stress action (Fig. 20 and Fig. 21). However, 
the specimens are three-dimensional materials even only the exposed surface was observed. Particles just below the observation plane can influence the measured behavior. The fracture mode in our Brazilian test is evident transgranular cracking (Fig. 24). The result could demonstrate that the tensile failure strength of particles must be lower than cohensive strength between particles and binder. The authors think it is reasonable to demonstrate the failure mechanisms of PBX simulant by the fracture surface morphology.

\section{Acknowledgements}

The authors of this paper acknowledge the financial support from the National Natural Science Foundation of China (grant number 10832003), the National Basic Research Program of China (grant number 613830202), and the Program for New Century Excellent Talents (NCET-06-0159). The authors also thank Professor Nie Fude from Institute of Chemical Materials, Chinese Physical Academy for providing PBX simulation materials.

\section{References}

[1] S. J. P. Palmer, J. E. Field, J. M. Huntley. Deformation, strengths and strains to failure of polymer bonded explosives. Proc. R. Soc. Lond. A. 1993, 440: 399-419.

[2] C. B. Skidmore, D. S. Phillips, P. M. Howe, et al. The evolution of micro structural changes in pressed HMX explosives. In proceeding: 11th International Detonation Symposium. 1998.

[3] P. W. Chen, H. M. Xie, F. L. Huang, et al. Deformation and failure of polymer bonded explosives under diametric compression test. Polymer Testing. 2006, 3(25): 333-341.

[4] P. W. Chen, F. L. Huang, Y. S. Ding. Microstructure, deformation and failure of polymer bonded explosives. J. Mater. Sci. 2007, 42(13): 5272-5280.

[5] P. J. Rae, S. J. P. Palmer, H. T. Goldrein, et al. White-light digital image cross-correlation (DICC) analysis of the deformation of composite materials with random microstructure. Optics and Lasers in Engineering. 2004, 41(4): 635-648.

[6] P. J. Rae, H. T. Goldrein, S. J. P. Palmer, et al. Moire interferometry studies of PBX 9501. Shock Compression of Condensed Matter. 2001, 825-828.

[7] P. J. Rae, S. J. P. Palmer, H. T. Goldrein, et al. Quasi-static studies of the deformation and failure of PBX 9501. Proc. R. Soc. Lond. A.2002, 458: 2227-2242.

[8] M. Li, J. Zhang, C. Y. Xiong, et al. Damage and fracture prediction of plastic-bonded explosive by digital image correlation processing. Optics and Lasers in Engineering. 2005, 43(8): 856-868.

[9] Z. W. Liu, H. M. Xie, K. X. Li, et al. Fracture behavior of PBX simulation subject to combined thermal and mechanical loads. Polymer Testing. 2009, 28(6): 627-635.

[10] A. L. Lewis, H. T. Goldrein. Strain measurement techniques in explosives. Strain. 2004, 40(1): 33-37.

[11] H. I. Goldrein, P. J. Rae, S. J. P. Palmer, et al. Construction of a high-resolution moiré interferometry for investigating microstructural displacement fields in materials. Phil. Trans. R. Soc. Lond. A. 2002, 360(1794): 939-952.

[12] H. M. Xie, H. Shi, P. W. Chen, et al. An experimental study on creep deformation of PBX with laser moiré interferometry method. Fracture and Strength of Solids. 2006, 306(6): 1037-1042. 
[13] P. J. Rae, H. T. Goldrein, S. J. P. Palmer, et al. 12 th International Detonation Symposium, 2002, 44-48.

[14] S. G. Grantham, J. E. Field. Speckle correlation methods applied to ballistics and explosives. Proc. of SPIE Vol. 4933, 27-32.

[15] S. G. Grantham, C. R. Siviour, W. G. Proud, et al. Speckle measurements of sample deformation in the split Hopkinson pressure bar. J. Phys. IV France. 2003, 110: 405410.

[16] S. G. Grantham, C. R. Siviour, W. G. Proud, et al. High-strain rate Brazilian testing of an explosive simulant using speckle metrology. Meas. Sci. Technol. 2004, 15: 18671870.

[17] C. R. Siviour, D. M. Williamson, S. G. Grantham, et al. Split Hopkinson bar measurements of PBXs. Shock compression of condensed matter. 2003,706(2): 804807.

[18] T. C. Chu, W. F. Ranson, M. A. Sutton, et al. Applications of digital image correlation techniques to experimental mechanics. Experimental mechanics. 1985, 25(3): 232244.

[19] D. Lecompte, A. Smits, S. Bossuyt, et al. Quality assessment of speckle patterns for digital image correlation. Optics and lasers in Engineering. 2006, 44(11): 1131-1145.

[20] W. G. Proud, M.W. Greenaway, C. R. Siviour, et al. Characterizing the response of energetic materials and polymer bonded explosives (PBXs) to high rate loading. Mater. Res. Soc. Symp. Proc. Vol. 896. 2006, 0896-H08-02.1-12.

[21] C. J. Tay, C. Quan, Y. H. Huang, et al. Digital image correlation for whole field out-of plane displacement measurement using a single camera. Optics Communications, 2005, 251: 23 36.

[22] H. W. Wang, Y. L. Kang. An improved digital speckle correlation method and its application in copper thin film. Proc. SPIE Vol. 2002, 4537: 151-153.

[23] K. P. Chong, M. D. Kuruppu. New specimen for fracture toughness determination for rock and other materials. Int. J. Fract. 1984, 26, R59-62.

[24] K. P. Chong, M. D. Kuruppu. Fracture toughness determination of layered materials. Eng. Fract. Mech. 1987, 28(1): 43-54.

[25] P. D. Peterson, K. S. Mortensen, D. J. Idar, et al. Strain field formation in plastic bonded explosives under compressional punch loading. Journal of Materials Science, 2001, 36(6): 1395-1400.

[26] K. Li Study on quasi-static and dynamic mechanical behaviors of polymer bonded explosive. Master degree thesis. Beijing: Department of Mechanics, Beijing institute of technology. 2008. (in Chinese)

[27] J. Zhao Applicability of Mohr-Coulomb and Hoek-Brown strength criteria to the dynamic strength of brittle rock. International Journal of Rock Mechanics and Mining Sciences. 2000, 37(7): 1115-1121.

[28] D. Williamson, S. J. P. Palmer, S. G. Grantham, et al. Mechanical properties of PBS9501. American Institute of Physics. 2004, 706: 816-819.

[29] C. Liu, C. M. Cady, P. J. Rae, et al. On the quantitative measurement of fracture toughness in high explosive and mock materials. In proceeding: In proceeding: $14^{\text {th }}$ International Detonation Symposium, 2010.

[30] S. J. P. Palmer, J. E. Field, J. M. Huntley. Deformation, strengths and strains to failure of polymer bonded explosives. Proc. R. Soc. Lond. A . 1993, 440: 399-419. 
[31] P. W. Chen, H. M. Xie, F. L. Huang, et al. Deformation and failure of polymer bonded explosives under diametric compression test. Polymer testing, 2006, 25(3): 333-341.

[32] P. W. Chen, F. L. Huang, Y. S. Ding. Microstructure, deformation and failure of polymer bonded explosives. J. Mater. Sci. 2007, 42(13): 5272-5280. 


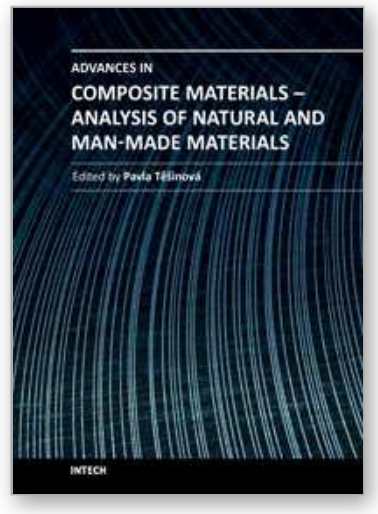

\author{
Advances in Composite Materials - Analysis of Natural and Man- \\ Made Materials \\ Edited by Dr. Pavla Tesinova
}

ISBN 978-953-307-449-8

Hard cover, 572 pages

Publisher InTech

Published online 09, September, 2011

Published in print edition September, 2011

Composites are made up of constituent materials with high engineering potential. This potential is wide as wide is the variation of materials and structure constructions when new updates are invented every day.

Technological advances in composite field are included in the equipment surrounding us daily; our lives are becoming safer, hand in hand with economical and ecological advantages. This book collects original studies concerning composite materials, their properties and testing from various points of view. Chapters are divided into groups according to their main aim. Material properties are described in innovative way either for standard components as glass, epoxy, carbon, etc. or biomaterials and natural sources materials as ramie, bone, wood, etc. Manufacturing processes are represented by moulding methods; lamination process includes monitoring during process. Innovative testing procedures are described in electrochemistry, pulse velocity, fracture toughness in macro-micro mechanical behaviour and more.

\title{
How to reference
}

In order to correctly reference this scholarly work, feel free to copy and paste the following:

Pengwan Chen, Zhongbin Zhou and Fenglei Huang (2011). Macro-Micro Mechanical Behavior of a HighlyParticle-Filled Composite Using Digital Image Correlation Method, Advances in Composite Materials - Analysis of Natural and Man-Made Materials, Dr. Pavla Tesinova (Ed.), ISBN: 978-953-307-449-8, InTech, Available from: http://www.intechopen.com/books/advances-in-composite-materials-analysis-of-natural-and-man-madematerials/macro-micro-mechanical-behavior-of-a-highly-particle-filled-composite-using-digital-image-correlatio

\section{INTECH}

open science | open minds

\section{InTech Europe}

University Campus STeP Ri

Slavka Krautzeka 83/A

51000 Rijeka, Croatia

Phone: +385 (51) 770447

Fax: +385 (51) 686166

www.intechopen.com

\section{InTech China}

Unit 405, Office Block, Hotel Equatorial Shanghai

No.65, Yan An Road (West), Shanghai, 200040, China

中国上海市延安西路65号上海国际贵都大饭店办公楼405单元

Phone: +86-21-62489820

Fax: $+86-21-62489821$ 
(C) 2011 The Author(s). Licensee IntechOpen. This chapter is distributed under the terms of the Creative Commons Attribution-NonCommercialShareAlike-3.0 License, which permits use, distribution and reproduction for non-commercial purposes, provided the original is properly cited and derivative works building on this content are distributed under the same license. 